\title{
Las lecciones del silencio: María Zambrano y José Gaos ANTE JOSÉ ORTEGA Y GASSET
}

\author{
Lessons From SilenCe: María Zambrano And José GaOs, \\ Disciples of José ORTEGa y GASSET
}

\author{
Roberto Sánchez Benítez* \\ DOI: http://dx.doi.org/10.29043/liminar.v19i2.842
}

Resumen: Los pensadores españoles María Zambrano y José Gaos fueron notables discípulos de José Ortega y Gasset, entendieron a su manera el "silencio" que su maestro guardó durante la guerra civil española, viviendo el exilio de manera singular. Sus interpretaciones remiten, por un lado, al problema de la palabra y el silencio que la circunda y la hace posible, sobre todo si es "profética", mientras que, por el otro, aluden al sentido que llegó a tener la figura del intelectual ante ese nuevo fenómeno inédito que dominó el escenario de las sociedades occidentales en el siglo XX, a saber, la "masa".

Palabras clave: guerra civil española, intelectuales, María Zambrano, José Gaos, José Ortega y Gasset.

Abstract: Spanish intellectuals María Zambrano and José Gaos were notable disciples of José Ortega y Gasset, who understood in their own way the "silence" that their mentor kept during the Spanish Civil War, living in exile in a unique way. Their interpretations refer, on the one hand, to the problem of the word and the silence that both surrounds it and makes it possible, especially if it is "prophetic", while, on the other hand, they allude to the meaning that the figure of the intellectual came to have given this new, unprecedented phenomenon that dominated this stage of Western societies in the 20th century, namely the "masses".

Key words: Spanish civil war, intellectuals, María Zambrano, José Gaos, José Ortega y Gasset.

\footnotetext{
* Roberto Sánchez Benítez. Doctor en Filosofía por la Universidad Nacional Autónoma de México. Profesor investigador en la Universidad Autónoma de Ciudad Juárez, México. Temas de especialización: ética y filosofía del derecho. Correo electrónico: sanchez005@gmail.com. ORCID: https://orcid.org/0000-0002-9481-9185
}

Enviado a dictamen: 12 de diciembre de 2020 Aprobación: 2 de febrero de 2021 


\section{La sustracción al delirio}

Yo también he callado - y muy radicalmentedurante todo este tiempo, porque en España no podía hablar y fuera de España no quería hablar. Algún día manifestaré por qué callé. José Ortega y Gasset

Duele, sí, no ha dejado de doler, este silencio de Ortega. Lo hemos sentido como una losa fría en los días de la guerra, en la soledad de Barcelona. María Zambrano

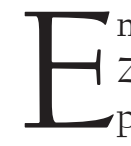
n la magnífica selección de escritos de María Zambrano dedicados a José Ortega y Gasset, que publicó la editorial Trotta (Zambrano, 201la), el compilador Ricardo Tejada se refiere a la forma en que la autora recrimina a Ortega su falta de compromiso y, sobre todo, el silencio que mantuvo sobre la situación española desde 1933. En 1934, Zambrano tiene 30 años y milita en la Federación Universitaria Escolar. Sin estar inscrita en ningún partido político, oscila entre la izquierda republicana y el PSOE. En julio de 1935 consigue la firma de Ortega, quien tiene 52 años, para un manifiesto de apoyo a la República, pero no logra, en cambio, que hable en Radio América, en la que la pensadora malagueña participaba: el maestro calla ante lo incomprensible de los hechos que preludian la guerra. Suceso que a Zambrano habrá de afectarle profundamente y cuyo sentido nos proponemos ahondar, sobre todo para quien le enseñó la "necesidad de pensar". El resentimiento, por llamarle de alguna manera, y más allá de lo cual quisiéramos ir, le impedirá impartir unas conferencias ya previstas sobre Ortega en los años cuarenta en Cuba, más no así seguir escribiendo sobre él y sus recuerdos a la luz de la memoria ante la ausencia definitiva acaecida con la muerte del pensador madrileño en 1955, llegando a decir, por ejemplo, que "Su muerte me ha hecho ver que le amaba aún más de lo que creía, que le amaré siempre. Estoy hace muchos años alejándome de ciertos aspectos de su pensamiento [...]. Eso no importa, seré su discípula siempre" (citada por Pereda, 2008:141). En dos momentos habremos de comprender dicho resentimiento, falta de misericordia o silencio, con los cuales Zambrano valora la presencia/ ausencia, dadas ambiguamente, en la actitud de Ortega en los años decisivos de la guerra civil española.

Gaos, por su parte, no solamente dedicó artículos relevantes al tema del profetismo orteguiano, que mencionaremos, sino que en la conferencia "Ortega en política”, ofrecida en el Ateneo Español en 1956, a un año de la muerte de su mentor, encontramos su versión sobre su silencio. Gaos data el "absentismo" político orteguiano a partir de diciembre de 1931, y prácticamente hasta su muerte,

fue el inicio de una falta de participación en la política de su patria que, prolongada hasta su muerte, debió de ser sentida por él como una amputación de su ser que debió de contribuir grandemente, si no exclusivamente, a que sobre todo la última veintena de años de su vida encerrase un entrañable amargor (Gaos, 1957:129).

Entre las razones que lo determinaron a guardar silencio no pudo haberse encontrado el miedo al destierro, que los tres personajes vivieron de manera singular, sino que reclamó para sí un "deber de callar, para no tener que mentir si en épocas como la nuestra quiere ser escuchado quien piensa como él" (Gaos, 1957:131). Pero Gaos también señala una auténtica imposibilidad de "estar con unos y con otros", ello referido a los bandos en disputa en la Guerra Civil. Además de que habría existido una imposibilidad para tratar, comunicar o comulgar con la "masa", de alguien que se entendió mejor con el "pueblo", con quien mantenía todavía un vínculo aristocrático. Ortega hubiera preferido una "república del pueblo", más que una de las masas. De cualquier manera, los dos discípulos orteguianos verán en este silencio una lección, aunque Gaos será más radical y lo entenderá como "el fracaso del intelectual en política” (Gaos, 1957:131).

Entre 1936 y 1940, en diferentes textos, Zambrano reprocha a Ortega, de manera directa o aludida, la falta de lealtad a la causa republicana. En 1936, en el artículo "La libertad del intelectual", recrimina, en general, "el 
asco del intelectual — del intelectual típico- por la masa", y lo conmina a que escuche la voz del pueblo. Sin embargo, es en el texto escrito a fines de 1939, o inicios de 1940, "Los intelectuales en el drama español. Los que han callado: Ortega y Azorín" que las recriminaciones son directas y fuertes, aunque encontramos ya una formulación profunda de la actitud silenciosa de Ortega: le echa en cara la falta de misericordia; la pretensión de renunciar al "delirio colectivo" que supone toda revolución y querer mantenerse al margen cuando ello implicaba el "mancharse". Ricardo Tejada comenta que los dos libros importantes publicados por Zambrano en 1939, Filosofía y poesía y Pensamiento y poesía en la vida española, ambos en México en su primera edición, figuran en la Fundación Ortega y Gasset con modestas dedicatorias que ya marcan un distanciamiento. Por lo demás, el crítico señala que no existe constancia de que Ortega los haya leído y que, de alguna manera, influyeran en su pensamiento.

Asimismo, Tejada anota que la carta de Zambrano dirigida a José María Chacón y Calvo, fechada el 4 de marzo de 1940 en La Habana, publicada en La Gaceta de Cuba, donde consta el rechazo a impartir las conferencias sobre Ortega, aparece mutilada en la edición La Cuba secreta (Zambrano, 1996), una antología de textos zambranianos escritos en la isla caribeña, precisamente donde se menciona el nombre de Ortega. La frase de marras afectada indica que "Ha llegado a mí la posición franquista de Ortega y ya es algo muy por encima de mis fuerzas el hablar sobre él". Tejada dice desconocer la razón por la cual la carta aparece mutilada. Zambrano no puede hablar de Ortega porque no puede soportar asociar la figura del maestro a la de "ellos" (los que atentaban contra la libertad y la república); verla al lado de "tanta y triste vaciedad espiritual". Congoja y angustia que la orillan al silencio donde, al parecer, encontró un vínculo comunicativo más allá de la palabra, al lado de la memoria, la estima y el dolor, y por el cual se ligará a la actitud de aquel, es decir, pretenderá guardar silencio, aunque no se trate estrictamente del mismo que tuvo Ortega ante la circunstancia de la España dolida en la segunda mitad de los años treinta. Única actitud que cree prudente frente a lo "incomprensible". Así, Zambrano se vio conducida a adoptar "un silencio que es el mejor homenaje que yo puedo hacer a mi maestro y a lo que me considero obligada por todo cuanto le debo. Cuando no se entiende a los que se ha admirado y querido, lo mejor, lo único, es callar... y tal vez, esperar todavía" (Zambrano, 201la:221). ${ }^{1}$

Es desde esta "serenidad" que Zambrano puede referirse a su maestro; desde "el silencio del corazón, desde el acallamiento de las pasiones" como lo sostendrá en el texto ya citado "Los intelectuales en el drama español. Los que han callado”. Ahí, le parece "inconcebible humanamente" ese silencio aterrador cuando lo que estaba enfrentando España era una "gigantesca y cruentísima purificación" (Zambrano, 20lla:241). El delirio de un pueblo que salía de su cárcel, del "laberinto de sus fantasmas". La falta de misericordia que le echa en cara a Ortega es entendida como "falta de capacidad de entrega, de olvido de sí [...] falta de amor, de caridad hacia la carne de nuestra carne [...] que ha pecado; falta de comunión con el pecador" (201la:42). Lo que le recrimina es el sustraerse al delirio, "el permanecer callados cuando todos gritábamos”, el permanecer lúcidos cuando todos habían renunciado a ello para quedar a expensas de la "lucidez que da el amor exasperado hacia algo que amenaza ser destruido ante nuestros [...] ojos". No se puede desconocer hipócritamente la locura que se apoderó del pueblo auténtico, "dejando intactas pequeñas islas de buen sentido”. De cualquier manera, Zambrano reconoció que Ortega tuvo que vivir la tragedia que sacudió a todos, si bien de manera cauta, prudente, la cual se prolongó en la soledad del exilio. Terminará preguntándose si en el silencio en el que queda su palabra en la memoria, al igual que en la de Azorín, no estará la auténtica esencia española, la mera existencia de España. “¿Será su silencio el trasunto humano de aquella indiferencia sagrada de la tierra?"(201la:246), esa que Zambrano veía como lo intangible, inatrapable, inveterado y eterno: la España anónima, intacta, virginal, algo sagrado que nada ni nadie es capaz de conmover: las faenas del campo, la tierra dando frutos, el trabajo monótono del 
labriego que ya en la cara lleva la tierra que cultiva y lo hermana con ella, las casuchas, la vieja a la puerta de la casa, la madre amamantando al hijo, la moza con el cántaro "camino de la fuente solitaria", en fin, el horizonte español que tanto lamentará dejar al partir hacia el exilio. Referencia al horizonte como forma de comprensión de la existencia que, sin duda, Zambrano aprendió muy bien de las Meditaciones cuando Ortega señala, refiriéndose a la sutil atención de los detalles mínimos y las cosas inmediatas cuyo sentido debemos "salvar", esto es, llevar a su plenitud, sobre todo cuando ello es arrojado por el naufragio del vivir:

Se atiende a detalles del paisaje español, del modo de conversar de los labriegos, del giro de las danzas y cantos populares, de los colores y estilos en el traje y en los utensilios, de las peculiaridades del idioma, $y$, en general, de las manifestaciones menudas donde se revela la intimidad de la raza (Ortega, 1994:24).

¿A ello corresponderá entonces ese silencio que no sería sino otra forma de pervivir en lo esencial o sagrado y que nada es capaz, ni las "teutonas bombas" de destruir? Lo anterior no puede desvincularse del estoicismo español, tal como lo entiende Zambrano, y que es esa manera precisamente de perdurar o afirmarse en el tiempo. Las viñetas españolas referidas casan enteramente con esa actitud de "naturalidad y entereza" con las que el pueblo español pareciera haber enfrentado muchas de sus calamidades. Un escenario donde la silueta del pensador se afirma en la soledad, el silencio, como elementos de una sabiduría imborrable, tal como lo señala en Pensamiento y poesía en la vida española, uno de los textos escritos en los primeros años del exilio. Señala ahí:

El estilo de nuestra vida sobria, vida de hombres silenciosos enteros y pensativos, sentados a la puerta de su casa o caminando a solas con sus pensamientos bajo el alto cielo español, parece estar de acuerdo con esta doctrina estoica que el mundo olvida y recuerda alternativamente en forma digna de ser notada (Zambrano, s/f).
A ello corresponde, finalmente el estilo oral — por más que el compendio de sus obras sostenga lo contrario-, con el cual Ortega figuraba más sus ideas que retraerlas a una genealogía conceptual, y con el cual buscaba mantener un contacto dialógico vivo, fermentador de ideas en sus discípulos, como lo recuerda Recaséns Siches:

Ortega puso siempre máximo empeño, con logrado éxito, en tratar todos los temas filosóficos, incluso los más difíciles, empleando el lenguaje más accesible, ora popular, ora literario, manejando con impresionante y brillantísima destreza imágenes y metáforas, para tratar las cuestiones filosóficas más arduas, lo mismo en la exposición de su propio pensamiento que en la explicación de los grandes clásicos (Recaséns, 1970:286).

\section{La inexorabilidad de los acontecimientos}

"Una voz que nace del silencio"2 es un artículo que María Zambrano publica en La Habana en 1940 a raíz de la aparición en 1939 de Ensimismamiento y alteración. Meditación de la técnica ${ }^{3}$ de Ortega, dos años después de haber estallado la guerra civil española y de haber, supone Zambrano, guardado silencio dos años antes de dicha fecha. El artículo se pregunta, con algo más que un reproche, por tal actitud que dejó en la orfandad a una generación que habría esperado de él algo diferente, al menos una palabra de condena por tan "terrible trance". Además de lo indicado, Zambrano piensa que dicho silencio fue una forma que tuvo Ortega de enfrentar lo que para él era el inevitable desastre en el que se hundía España, esto es, que se trató de un silencio deliberado, "producto de la reflexión más cuidadosa, tan producto de la meditación como sus palabras" (Zambrano, 201la:75). A ello contribuyó lo que recuerda de las alusiones que Ortega hacía del profeta, quien nunca habría "podido impedir jamás que ocurra la catástrofe que profetiza" (201la:75). Profetismo, que según unos apuntes que Zambrano conservó de una de sus clases, habrá de estar "contra la opinión pública", y en lo que Gaos habrá de insistir, de manera esencial, como veremos. Forma de hablar que habría cultivado desde 
1933, y que le pareció aterradora a Zambrano: entre la profecía y el silencio ante los acontecimientos atroces que se veían venir. Zambrano entendió que el silencio de Ortega era vaticinador: precede y anuncia la catástrofe. Es el silencio que precede a la tormenta, y cuyos aires Zambrano describe de manera puntual:

Un aire denso, una atmósfera poblada de raras luces, un algo terrible y al par grandioso, sentíamos los españoles que se iba cerniendo sobre nuestras cabezas. Hasta tal punto que el romper de la tormenta fue acogido con una especie de dilatación del pecho un tanto suicida. Tiempo éste inmediatamente anterior al tiempo sin tiempo de la tragedia, que no ha sido por nadie fijado en su complejidad (Zambrano, 201la:76).

Así, el silencio de Ortega frente al inminente estallido de la Guerra Civil no tiene únicamente los visos del afianzamiento en una postura reaccionaria o antirrevolucionaria, ni tampoco el pensador estaría con ello traicionando la figura ligada al pueblo que Zambrano siempre conservó de sus inolvidables paseos por las afueras de Madrid, cuando el maestro invitaba a un grupo selecto de estudiantes a continuar las conversaciones académicas. Las razones de este silencio son más profundas y tienen que ver con el sentido de la palabra, incluso puede entenderse que lo que insinúan los silencios de Ortega es más eficaz que lo que expone "a las claras" con su acción, aún en las sombras más terribles, preludio de la catástrofe, con una conciencia que es inteligencia quintaesenciada, es decir, con una forma de suponer la acción del pensamiento sobre la vida. Para Zambrano, silencio y palabra nacen de la misma raíz, con igual significado hondo, "y de una conciencia más clara y como tal más dramática, de la inexorabilidad de los acontecimientos" (201la:76). Algo que ya la fenomenología, a la que era tan afecta la pensadora malagueña, había señalado: "debemos considerar la palabra antes de que ella sea pronunciada, el fondo de silencio que no deja de rodearla, sin el cual ella no diría nada, o aún poner al desnudo los hilos de silencio con los cuales está entremezclada", señaló alguna vez Merleau-Ponty (2006).
Lo que el silencio de Ortega testimonia es, de esta manera, una forma de ser del pensamiento que se abisma en la vida para formular sus posibilidades, esto es, que lleva a la actualidad lo que yace "oculto en la posibilidad". Algo que Zambrano vio expuesto en las Meditaciones del Quijote (1914), en el afán orteguiano de "reformar la vida española", de sacar de ella misma sus posibilidades; libro que la niña Zambrano encontró en la biblioteca de su padre y que creía que en verdad había sido escrito por el Quijote. Reformar y salvar, tal será el sentido del llevar "a la plenitud de su significado" todo lo que la vida presente en una actitud o pasión que solo puede ser amorosa; búsqueda del sentido que resuena en la famosa sentencia "Yo soy yo y mi circunstancia, y si no la salvo a ella no me salvo yo" (Ortega, 1994:30). En las Meditaciones, Ortega sostuvo que el ideal consiste en hacer de cada cosa el "centro del universo". El sentido que habrá de potenciarse es el reflejo del todo en cada cosa, la manera en que la existencia virtual de una existe en otra, la forma en la que coexiste con las demás, todo esto dicho con una fuerte inspiración leibniziana; por ello, el sentido es la "sombra mística que sobre ella [la cosa] vierte el resto del universo" (Ortega, 1994:77).

De ahí el "amor intelectual" que impulsó Ortega y que Zambrano no dejó de reconocer en ningún momento. Señala Ortega: "Hay dentro de toda cosa la indicación de una posible plenitud. Un alma abierta y noble sentirá la ambición de perfeccionarla, de auxiliarla, para que logre esa su plenitud. Esto es amor —el amor a la perfección de lo amado" (1994:12). El amor es lo que liga las cosas y las funde con nosotros. Retomando a Platón y, por supuesto a Spinoza, además de Leibniz, ${ }^{4}$ Ortega sostuvo que el amor es lo que hace posible que el universo viva en conexión. De cada aspecto de la vida, de cada cosa insignificante, es posible extraer el espíritu que encierra, su logos. En la medida en que busquemos para nuestra circunstancia, en lo que tiene de limitación y peculiaridad, "el lugar acertado en la inmensa perspectiva del mundo", es que la "reabsorción" en ella será nuestro destino. Por ello, la meditación resulta ser un "ejercicio erótico", mientras que el concepto se convierte en un "rito amoroso". 
Es ese silencio el que acompañó a Zambrano en el momento de traspasar las fronteras para iniciar un exilio de más de cuarenta años en el cual, no la voz, sino la figura del maestro, le hizo entender la labor de la conciencia y del recuento, de recuperación y vida que comenzará a partir de entonces. Habrá de sentir, en el vacío y salto del paso dado que abandona la tierra natal, "una deuda, un deber", a saber, "recoger esa experiencia [la de la guerra], de clarificar en enseñanza, en clara y compleja 'razón de amor', todo el dolor, de todo un pueblo" (Zambrano, 201la:80).

Para la misma Zambrano, la palabra obedece al pensamiento, el cual está orientado o establecido por los ritmos de la vida, por sus formas de acontecer a partir de oscilaciones entre presencia y revelación; sinuosidades por las que transcurre el pensar, "claros" en los que se detiene para tener la oportunidad de remontarse al sentido profundo de la palabra, al retorno de voces entredichas, a las revelaciones interiores de un misterio del que se hará eco. Claros que son "agujeros del silencio" que caracterizan el estado reflexivo, definido por una aspiración a ser, es decir, a lo inasible de cada momento. La tarea reflexiva se instala frente a lo imposible, pero también ante la pérdida o fuga del pensamiento inatrapable, es decir, frente a lo imposible de ser recobrado. Palabra que queda en vilo por aquello que no podrá ser dicho a pesar de su presencia.

Es el uso de la palabra el que caracteriza al intelectual. Aspecto que, como hemos mencionado, Zambrano relaciona con el senequismo español de perder la vida o ser un muerto viviente. Tal uso de la palabra debería comprometer al intelectual con la historia colectiva, sobre todo ante la sorpresa de los acontecimientos inesperados, terribles, ahí donde la acción sobre la vida debería estar dibujada por la palabra misma. La palabra es exposición, rostro del intelectual, forma del pensamiento y sentido de la acción; exteriorización de las ideas, a la vez que conciencia de sí mismo. Palabra, espejo de los demás, revelación. Muchos años después del inicio de su exilio, y prolongándolo, en 1977, Zambrano sostuvo a propósito de la vinculación del intelectual con la palabra:
Y así el llamado intelectual [...] no viene a ser otra cosa que el que da su palabra, el que dice y da nombre o figura a lo visto y sentido, a lo padecido y callado, el que rompe la mudez del mundo compareciendo por el solo hecho de haber nombrado las cosas por su nombre, con el riesgo tan cruel de no acertar con la palabra justa y el tono exacto en el momento exigido por la historia (Laffranque 1984:106).

Y, como si estuviera recordando su reclamo a Ortega, señala que:

Y el estigma de no haber comparecido o de haberse fatigado antes de tiempo, de andar distraído y aun absorto en el mejor de los casos; de haberse confiado también, o el de haberse envuelto en la desconfianza; de haber dicho demasiado o muy poco, antes o después, más no entonces, en el instante decisivo, que no vuelve si lo ha dejado perder (Laffranque, 1984:106).

Son las enseñanzas de Séneca las que se imponen en esta evaluación de la responsabilidad del pensador con relación a su tiempo y vida, y las que Zambrano pareciera estar contraponiendo a Ortega. Tales enseñanzas corresponden tanto a los descubrimientos interiores, a la expresión de la "integridad del alma profunda", como al destino, en donde se busca recorrer el camino por ellas descubierto, es decir, hacer de cada vida un camino. La enseñanza senequista se sintetiza en vivir la derrota o la desdicha, como habrá de ser exigido por Zambrano ante el exilio español, el destierro al que se vieron obligados, abandonando la cultura y las posiciones en las que se reconocían, y frente a lo cual murieron de alguna manera. Caída, derrota personal y colectiva, que mucho tenía que ver con la decadencia de Occidente, representada cruelmente por el nazismo, que Zambrano resintió de manera cercana por el confinamiento francés que sufrieron su madre y hermana en la ocupación nazi. Aceptación del sufrimiento "de mirar y decir el desastre", como lo señala Laffranque (1984). El mutismo fue, a fin de cuentas, una forma de la resignación estoica, una de las tres opciones que tendrá el intelectual frente a la decadencia señalada; las otras dos serán la tarea artística 
representada por las vanguardias, como el surrealismo, y la que ha correspondido al militantismo combatiente.

La forma de entender el silencio de Ortega tiene mucho que ver con el senequismo que Zambrano siempre retuvo en su formación, ya que vio en esta tendencia una resignación ante los acontecimientos, de forma que podría representar el fracaso del intelectual ante el poder por no admitir la función de las políticas, o de los políticos, como bien señala Laffranque (1984), aspecto que igualmente será señalado por Gaos, como veremos en la segunda parte de este ensayo. Séneca o de la resignación.

Así, lo que fue determinante para la propia Zambrano fue convertir la tragedia en conocimiento (algo que Carlos Fuentes repetía incansablemente cuando recordaba a la pensadora malagueña). Como una lección de la misma, tuvo que aprender a respetar el silencio de Ortega, quien ya había logrado respeto precisamente a partir de su palabra y conducta. El sentido trágico que Ortega despliega en el más platónico de sus textos, las Meditaciones - según Zambrano-, es para que la vida afronte la luz, la transparencia, para que quede "bañada por ella". La transparencia como la meta del nuevo filosofar. A fin de cuentas, el proyecto de la Razón vital, histórica, viviente, no es otro que el que la "Razón se disuelva a sí misma a fuerza de entenderse; que la vida se apure, para dejar, celosa, de ocultarse. Que vida y razón no se oculten la una a la otra" (Zambrano, 201la:107). Como Platón, Ortega verificó el tránsito de la tragedia a la filosofía.

Finalmente, tendríamos que indicar un último aspecto sobre la comprensión zambraniana del silencio orteguiano que tiene que ver con el momento climático de la salida al exilio, y que veremos recuperado en los textos que, por ejemplo, le dedicó a Ortega en las décadas de los cuarenta y cincuenta, precisamente ante el silencio más fructífero, el producido por su muerte, esto es, la función del discípulo, de aquel que debe proseguir la palabra del maestro y que tiene que ver con esa transformación aludida de la tragedia en conocimiento, algo que también Zambrano aprendió de él, es decir, la reformulación del dolor. La experiencia del exilio le hizo entender el silencio como parte de un magisterio que será congruente con las ideas que Ortega tenía sobre la realidad, la razón vital y el papel del ser circunstanciado. Silencio que le permite volver a la figura, filosofía y personalidad del maestro, pero con los logros de una discípula que ha sabido encontrar su propio camino y autenticidad en el filosofar, como insistirá varias veces. La palabra primera que escuche de Ortega, en las lecciones que reciba de él, le permitirá descubrir la necesidad del pensamiento. La palabra que profiera Zambrano posteriormente habrá de autocomprenderse en la gestación simultánea de un silencio que ni la muerte podrá contener. Es la soledad, y el silencio obligado que la circunscribe, lo que la conduce a adentrarse en sí misma y pensar a partir de sí, no con "los pensamientos del maestro, sino desde el orden y la claridad que ellos dejaron" (Zambrano, 201la:89), y a partir de la autenticidad que fueron preparando.

Es de este silencio último del que brota la palabra auténtica, tal como lo sostuvo Martin Heidegger, a quien resulta indispensable incluir en esta apreciación. Señala el autor de Sery tiempo: "Un resonar de la palabra auténtica sólo puede brotar del silencio" (citado por Vattimo, 1992:72); ${ }^{5}$ algo que la poesía o, en su caso, el pensar poetizante pueden llevar a cabalidad, en nuestro caso, la razón vital. La palabra auténtica es, para Heidegger y Zambrano, la palabra inaugural (auroral, dirá la segunda), la que hace acaecer verdades, es decir, nuevas aperturas de horizontes históricos. Por ello, el decir auténtico no puede más que ser un "callar simplemente del silencio" (Heidegger citado por Vattimo, 1992:74). La relación entre el silencio, la palabra auténtica y la muerte también habrá de desprenderse del pensamiento heideggeriano, tal como lo señala Vattimo: "la relación del lenguaje con el silencio se entiende sólo si uno se reclama a la doble función, fundante y desfundante, que tiene el ser-para-la-muerte" (1992:75). Sin que podamos desarrollar estos aspectos esenciales de las estructuras del Dasein heideggeriano, diremos simplemente que la anticipación de la muerte funciona como fundación del lenguaje, de la temporalidad, del horizonte del mundo y de la existencia como continuidad histórica. El Dasein se constituye como un todo continuo solo en referencia a una discontinuidad esencial (la muerte, la nada, el silencio). 
Únicamente puede ser un todo, tener una existencia como "tejido de eventos, de palabras, de significados", señala Vattimo, solo en cuanto se decide por la propia nulificación, el Abgrund o abismo que nos muestra "en la base a la continuidad de la experiencia, la nada y la muerte" (1992:77).

Algo de esta circunstancia del silencio ante la inminencia, e inmensidad, de los desastres, la guerra y la muerte retoma Zambrano cuando, en Notas de un método (1989), el último de sus libros, revire hacia Ortega y lo que ahí llama el "método del naufragio". Es esta circunstancia la que hace posible el pensar; revelar tal condición es ya una función del pensar, dicho de otra manera, solo "in extremis" el hombre piensa. "La muerte sería, por tanto, la insustituible presencia que hace nacer el pensar, que a su vez procura la autenticidad del sujeto" (Zambrano, 201lb:70). Cercanía con la muerte que, le parece a Zambrano, apenas habría vislumbrado Ortega con la tímida metáfora del "naufragio". Se trata de la idea de sumergirse en la vida, lo que ya había aprendido con Ortega y la "reabsorción de la circunstancia", tema que ya aparece en las Meditaciones, en una relectura que hace de sus obras en 1933 ("contagio de autenticidad"), y que no es otra manera de "abrazarse a lo que nos limita, sujetándose libremente a lo que encadena", sino "encontrar la libertad en la lucha y jamás en la evasión” (Zambrano, 201la:69). Tal reabsorción de las circunstancias constituye el destino concreto del ser humano. Por ello, al orteguiano "el hombre ha de hacerse su vida", Zambrano agregará que más bien "ha de ir cobrando su ser en su vida"; nacimiento interminable del hombre, gracias al cual no se agota en un tiempo y lugar; inabarcabilidad de la que nace igualmente el pensar.

\section{La derrota del intelectual en la política}

José Gaos entendió el silencio de Ortega de una manera inquietante, igualmente profunda, aunque con un énfasis marcadamente político, a diferencia de la interpretación zambraniana. El silencio que habrá de entender ya se escuchaba por toda Latinoamérica, por cierto, y no era él el único en sostenerlo: muchas voces "censuraban su ominoso silencio respecto a la
Guerra Civil española, su vinculación a grupos conservadores y profranquistas en Argentina, así como la decadencia progresiva de sus disertaciones orales e impresas" (Valero, 2015:94). Apreciación que, según cuenta el propio Gaos, pudo externarle al autor de las Meditaciones sin que lo contradijera. La versión de Gaos gira a partir de ese rasgo en la obra y personalidad orteguianas relativo a la "predicción", desarrollado fundamentalmente en el erudito ensayo gaosiano "La profecía en Ortega” de 1947, pero también a partir del cambio de relación que el maestro tuvo con el "pueblo" y la "masa". Detengámonos un poco en lo segundo para después señalar la "salida" interpretativa que Gaos elaboró del "silencio" de su maestro. ${ }^{6}$

Para Ortega, en La rebelión de las masas (1937), la "masa" es el "hombre medio" (Ortega, 1969:39); representa una conversión de "lo que era meramente cantidad - la muchedumbre - en una determinación cualitativa: es la cualidad común, es lo mostrenco social, es el hombre en cuanto no se diferencia de otros hombres, sino que repite en sí un tipo genérico". Pero también: "Masa es todo aquel que no se valora a sí mismo — en bien o en mal- por razones especiales, sino que se siente 'como todo el mundo' $y$, sin embargo, no se angustia, se siente a sabor al sentirse idéntico a los demás" (Ortega, 1969:40). A la masa pertenecen quienes no se esfuerzan por ser diferentes o por enfrentar los retos de que está llena la vida: "para ellas vivir es ser en cada instante lo que ya son, sin esfuerzo de perfección sobre sí mismas, boyas que van a la deriva." Lo que distingue a la masa es ese conformismo que la lleva a ser lo mismo siempre, sin que se exija más allá de lo que es capaz de dar. Por ello es que esta división, "masa" y "minorías", que analiza Ortega, no tiene nada que ver con el concepto de "clase social", sino con "clases de hombres". Es decir, que aún dentro de una clase social se puede encontrar dicha división, siendo notorios los cambios en declive de la "clase intelectual", así como los que aparecen en las clases trabajadoras encaminadas hacia una distinción cultural. Se trata, en términos generales, del estado psicológico del "hombre medio", cuya primera aparición Ortega ubica en Estados Unidos. 
Lo que preocupa a Ortega no es esta conversión positiva selectiva de la masa hacia los bienes culturales de las minorías, sino que ahora se conviertan en un motor visible de la vida pública política y lleguen a dominar incluso el sentido que antes tenían dichos bienes en las sociedades, dictando sus propias leyes, las cuales no se derivan de una estratificación social ni de un saber heredado por la tradición de gobierno, sino a partir de una "hiperdemocracia". Aspecto que habrá de contrariarlo en la medida en que reconoce que siempre lo animó una interpretación de la historia "radicalmente aristocrática": "Hoy asistimos al triunfo de una hiperdemocracia en que la masa actúa directamente sin ley, por medio de materiales presiones, imponiendo sus aspiraciones y sus gustos" (Ortega, 1969:42). La masa da vigor de ley a sus "tópicos de café", señala Ortega. Es la "vulgaridad" la que ha terminado por imponerse en las sociedades industrializadas, ahí donde lo que emana de la masa no tiene ningún respaldo intelectual o, al menos, juicioso. La masa, en la medida en que es indiferente para con lo que no es ella, es capaz de arrollar "todo lo diferente, egregio, individual, calificado y selecto". Sin duda que esa "eliminación" de lo que no es como la masa es la que Ortega (1969:45) llegó a sentir, como un intelectual que consideraba su vocación equivalente a la de "maestro" para el "pueblo". La masa ahora no sigue a las "minorías", "no las respetan, sino que, por el contrario, las dan de lado, las suplantan". Ortega sabía que su tiempo como maestro estaba terminando al cambiar y consolidarse el fenómeno de la masa en sociedades europeas que acabarán enfiladas por el camino sangriento de la Segunda Guerra Mundial. Gaos entendió muy bien este giro, aunque se concentró en el aspecto "profético" del estilo de escribir y pensar de su maestro, sin dejar de referirse a su declive como intelectual. ${ }^{7}$

Ortega vincula el ascenso de la masa con el declive de los imperios y la opulencia de las construcciones colosales, como ocurrió en Roma. Siente que quien no haya llegado a sentir miedo o estupor ante el "imperio de la masa" poco ha entendido del destino contemporáneo del ser humano. La masa está ahí, a semejanza de las construcciones imperiales, "i[...] colosal, instalada sobre nuestro tiempo como un gigante, cósmico signo de interrogación, el cual tiene siempre una forma equivoca, con algo, en efecto, de guillotina o de horca, pero también con algo que quiera ser un arco triunfal!" (Ortega, 1969:45). De cualquier manera, Ortega vio en el fenómeno de la masa un ascenso del "nivel histórico" de la humanidad: "Todo el bien, todo el mal del presente y del inmediato porvenir tienen en este ascenso general del nivel histórico su causa y su raíz" (Ortega, 1969:47). A fin de cuentas, a Ortega le parece que las masas carecen de moral, y eso es lo más grave: detentadora de derechos, pero carente de obligaciones. La "rebelión de las masas" es consecuencia de la desmoralización de Europa, de su fragilidad y de la incertidumbre del futuro, del estado precario y provisional en el que ha caído puesto que lo que se ha creado en el "interregno" de una época a otra no proviene de una necesidad auténtica ni tampoco tiene raíces suficientes como para corresponder al fondo sustancial de la vida. Por lo demás, y para cerrar nuestro paréntesis, habría que señalar que Ortega nunca estuvo de acuerdo con el "comunismo", algo que, de cualquier manera, Zambrano no señala en las consideraciones que hemos traído a colación. Le parecía que dicho movimiento resultaba ser una "sustancia inasimilable", además de que el europeo no vio en ello un "aumento de la felicidad humana” (Ortega, 1969:158), aunque no descartaba que se pudiera implementar en la medida en que ello salvara la circunstancia del vacío existencial en que se encontraba viviendo, ya sin moral alguna, sin sentido y en total apatía.

En "La profecía en Ortega", Gaos explora, como nadie lo había hecho, y como si se tratara de un continente recién descubierto, uno de los temas esenciales de su maestro, el cual alcanza un nivel de "profetismo" poco usual en los pensadores, al grado de convertirse incluso en su estilo de escritura y, por ende, de pensamiento. Tipología a la que Gaos presta toda su inteligencia y conocimiento de la obra orteguiana. Entre los ejemplos que cita Gaos, elegimos dos que, de alguna manera, son recurrentes en su análisis por 
lo representativo que son, pero que además permiten anclar nuestro tema de manera específica. El primero se encuentra en las Meditaciones del Quijote:

Creo muy seriamente que uno de los cambios más hondos del siglo actual con respecto al XIX, va a consistir en la mutación de nuestra sensibilidad para las circunstancias... Conforme la lejanía va dando al siglo último una figura más sintética, se nos manifiesta mejor su carácter esencialmente político... Lo otro, la vida individual, quedó relegada, como si fuera cuestión poco seria e intrascendente... ¿ ¿Cómo duda de que un día próximo parecerá esto increíble? (Ortega, citado por Gaos, 1957:19).

El segundo se ha ido cumpliendo de una manera extraña, con otro sentido al predicho por Ortega; corresponde al ensayo Biología y pedagogía (1921):

\section{Bien sé que a la hora presente me hallo solo entre mis contemporáneos para afirmar que la forma superior de la existencia humana es el deporte... la marcha de la sociedad, junto con los nuevos descubrimientos de las ciencias... anuncian un viraje de la Historia hacia un sentido deportivo y festival de la vida (Ortega, citado por Gaos, 1957:19-20).}

Precisamente ahí donde se sentía solo ante el advenimiento de una inédita sociedad de masas fue que pudo tener el presentimiento de su futuro caótico y, en consecuencia, de la actitud que finalmente llegó a tener frente a ellas, traducida en hostilidad, temor, aversión —que no dejan de ser, de cualquier manera, elementos previsores detectados por Gaos-. Previsiones que se convirtieron en profecías:

Parece, pues, que sólo queda pensar que lo predicho en el cuerpo "de las masas" era probablemente hostil, repugnante a lo más peculiar de la personalidad de Ortega y que el temor, la aversión sean emociones y mociones más `́previsoras’, más clarividentes que otras de signo más positivo (Gaos, 1957:51).
Esta nueva fisonomía social resultará contraria en efecto a la labor intelectual, al deseo de intervenir e influir en la vida pública definida como una vocación en la que creyó Ortega como "maestro", y a la que se dedicó con fervor, sobre todo a partir de su intervención en la prensa española de las primeras décadas del siglo XX. Gaos presenta una síntesis de esta fisonomía del "cuerpo de las masas", esbozada por Ortega, frente al cual se define su actitud que habrá de redundar en el escepticismo, la soledad y el silencio; actitud que Gaos llega a identificar como de "gran brahmán" y que, de alguna manera, es conveniente para convertir "en ciencia el conocimiento que los humanos tenemos de nosotros mismos, es decir, cada uno de los demás y de sí propio" (Gaos, 1957:25). Señaló Ortega:

La socialización, el imperio de las masas, la acción directa, el rebajamiento del nivel medio, la invasión de los bárbaros vertical, la persistencia de la violencia, aún bajo la sola forma de la acción del Estado, la peligrosidad de éste, el empleo de sus fuerzas por las de orden público según sus propios intereses, la abolición del reinado de la inteligencia o intelectualidad, la barbarie por inferioridad del hombre relativamente a su civilización [...] (Ortega, citado por Gaos, 1957:52).

Lo de Ortega fue entonces un pensar emocional ligado al presentimiento y, por tanto, a la predicción, ejercida en cuestiones morales y políticas, en donde toda la circunstancia orteguiana, contingente, futurista, estaría presente; condiciones que, por lo demás, hacen posible el lenguaje mismo, como señala de manera brillante Gaos (1957:65): "El hombre, contingente, futurista, emocional, emotivo, pre-vidente, y diciente, sería prediciente". Durante la "expatriación", Ortega publica poco, a diferencia de su producción anterior: es el momento de la guerra civil española, el franquismo, la Segunda Guerra Mundial, la postguerra; silencio que prácticamente lo hizo "callar".

Gaos señala, en el texto "Los dos Ortegas", que existió en efecto una "renuncia" o "neutralidad" del pensador a tratar de influir en la vida pública luego de que el entusiasmo por la República despareciera 
en la guerra civil española: "la neutralidad entre la República y sus enemigos, entre el franquismo y la emigración republicana" (Gaos, 1957:92). Neutralidad motivada por el predominio de lo político en detrimento de las ideas y de su acción constructiva en la sociedad, la cual se extenderá incluso al momento de la restauración, el que corresponde a lo que Gaos llama el "segundo Ortega" y que abarca los últimos treinta años del pensador español. Ese Ortega está "predominantemente inquieto, y hasta atemorizado; en todo caso, indignado, amargado; y si no definitivamente pesimista, tan dubitativo acerca del futuro, que pasa de creer en la profecía histórica a tener la vida humana por imprevisible" (Gaos, 1957:94). Gaos no duda en sumar en una unidad compleja la actitud del segundo Ortega, ahí donde la vocación de enseñanza tropezaba con la nula influencia sobre acontecimientos que ya se venían desarrollando: "La aversión y la impotencia juntas llegan a promover la indignación más resentida y airada" (Gaos, 1957:98). Y remite al texto de Ortega "El intelectual y el otro", que es "como un grito de anatema arrojado contra aquello que más contraría, a su vez, al intelectual, que en el fondo se siente impotente contra ello" (Gaos, 1957:96). Gaos ve en ello algo extraordinario, relacionado con esa naturaleza profética que pudo tener Ortega ahí donde "lo ingrato" pareciera anunciar su cumplimiento, y ante lo cual el pensador no pudo más que convertirse en un espectador de lo "incoado":

La profecía sería oriunda, ya del afán de lo grato, ya del temor a lo ingrato. $Y$ las potencias de la repugnancia, de la indignación, del temor, mucho más videntes que las de la complacencia. El afán de lo grato causaría ilusión acerca de su advenimiento. Cuando se reconoce el de lo ingrato, a pesar propio, será que adviene efectivamente (Gaos, 1957:96).

Gaos se detiene en la paradoja de un Ortega que a partir de la Guerra Civil escribe, crea y publica menos: se ha alejado de las circunstancias y pareciera contemplarlas, además de con cierto esteticismo, con horror paralizante y quizá desmoralizante, buscando incluso hacer caso omiso de las circunstancias "ingratas". Un tema que, de cualquier manera, seguirá abierto por el resto de su vida. Ortega habría desarrollado una actividad meramente contemplativa (así le llama Gaos en función de que la misma se habría realizado después de las Meditaciones del Quijote, cuando comienza el proyecto editorial de El Espectador). El "contemplar" va a formar parte del proyecto de "salvación" de las circunstancias, al menos, para traerlas a colación y ser pensadas, según sostiene Gaos en la famosa conferencia que impartió en el Casino español, en la Ciudad de México, en 1955, a la muerte de aquel, llamada "Ortega y España". Contemplación que forma parte del pensar, de poner en alerta y la atención sobre dichas circunstancias, pero que se encuentra inscrita en una labor periodística; estilo que acabará dominando polémicamente su obra en general, y que dificultará, en algún momento, el que sea reconocido como filósofo o pensador. Opción deliberada de estilo donde Ortega se daba cuenta de que no había otra forma de lograr cierta "eficiencia social", dado que las "formas de la aristocracia" habían sido ya estériles en España: "Quien quiera crear algo — y toda creación es aristocracia - tiene que acertar a ser aristócrata en la plazuela" (Ortega, citado por Gaos, 1957:108). Esta vocación periodística, por otro lado, ha prevalecido en la historia del ensayo social y cultural hispanoamericano desde el siglo XIX, con notables exponentes como José Martí, Domingo Faustino Sarmiento, Manuel González Prada, Eugenio María Hostos, Rubén Darío, José Enrique Rodó, Fernando Ortiz, José Carlos Mariátegui, Alfonso Reyes. Estilo que es asimismo una forma de intervención pública y política.

En la conferencia mencionada, Gaos vuelve sobre el tema de lo que ahora llama una "imposibilidad" convertida en un "patético drama" establecido entre la dificultad para alistarse entre los "defensores de la República” y los "sostenedores del régimen actual de España", es decir, de la dictadura. Ello en la medida en que, hasta antes del exilio, Ortega se asumía como maestro de su patria, situación que después se volvió penosa para él en el exilio. Sentimiento de insatisfacción, sin duda. Al mismo momento que Ortega vive 
lo anterior, Gaos asocia la transición del concepto de "razón vital" a la "razón histórica", en donde precisamente la razón se mostrará "impotente para hacerse oír", por lo que "quien quisiere ser el portador de la razón no tiene más conducta decente y posible que seguir sino la de callar en un rincón” (Gaos, 1957:113). Encallamiento en el silencio, más no "canallada". Es en esta conferencia donde aparece el juicio lapidario de Gaos en el sentido de que el caso de Ortega ha ilustrado el fracaso del intelectual ante la política en el siglo XX, representado en el silencio durante la guerra y la posguerra civil españolas: la "abstención política”. A fin de cuentas, a Gaos le pareció que, en efecto, se trató de una "auténtica imposibilidad" de estar "con unos y otros", ello referido a los bandos que la conformaron. Y resume, de manera notable en el texto "Ortega en política" de 1956, el desiderátum orteguiano en la política ligada a la filosofía, relación ya establecida por los griegos:

\begin{abstract}
para ser más que mentor de nuestro tiempo, protagonista de sus luchas, le faltó la capacidad para comunicar o comulgar con los más, con las masas; para ser puro mentor con éxito, le sobró la tentación y tentativa de entrar en competencia por el poder con los políticos; para ambas cosas, le faltó paciencia histórica o le sobró impaciencia histórica (Gaos, 1957:137)
\end{abstract}

\section{Conclusión}

Si pudiéramos retomar a Vattimo, podríamos decir que el silencio, a partir de las consideraciones importantes que Zambrano realiza sobre Ortega, es no solo "el horizonte sonoro que la palabra necesita para resonar, para constituirse en su consistencia de ser: es también el abismo sin fondo en que la palabra pronunciada, se pierde (Vattimo, 1992:77, cursivas en el original). Como hemos visto, si Ortega callaba era porque, en ocasiones, no encontraba la palabra adecuada, quedando el gesto de su búsqueda, algo que recuerda muy bien Zambrano cuando lo veía trastabillar, casi balbucear ante la negación misma de la palabra a ser, y de la cual se llevaba, quizá para mejor pensar, su ritmo, el tono. Antes que hablar, escuchaba la palabra que insistía en nacer y ello lo obligaba a callar más. De alguna manera, se dirigía más hacia sí mismo en una tarea meditativa, que ya es otra forma de pensar. Zambrano recuerda esos momentos que eran atmósferas creadas a su alrededor, donde el pensador iba más bien hacia sí mismo: "Se le sentía adentrarse en un espacio íntimo, en un medio propio fluido y transparente como agua; una atmósfera en la que la inteligencia se mueve por ser a ella adecuada" (Zambrano, 201la:128). Caridad intelectual, le llamará finalmente la pensadora.

Por su parte, Gaos consideró que Ortega no pudo ser "un hombre de nuestro tiempo ni para nuestro tiempo". Vivió de manera anticipada una incongruencia caracteriológica que ahora se ha vuelto dominante, entre una personalidad individual y las "dominantes en la colectividad". Contrariedad que se constituye como "uno de los hilos de irracionalidad que traman con la urdimbre de la razón del tejido de la historia" (Gaos, 1957:137). De la misma manera, si había que salvar "las circunstancias" de su maestro, Gaos supo articular, de manera conciliatoria, y buscando ir más allá de su maestro para encontrar la razón de su ser (el de él y el suyo), el conjunto de la trayectoria política de Ortega en el afán liberalista y en el sentido de una razón histórica, esto es, en la libertad y autenticidad otorgadas al individuo y a los grupos que van viviendo históricamente. Hermenéuticamente hablando, solo de un interés comprensivo puede surgir la compasión hacia actitudes que resultan disonantes, fuera de tiempo, como fue el caso de un silencio que se ha querido comprender. Así como resultó infructuosa la tarea de Ortega de elevar su pensamiento a la forma de un sistema filosófico en sus últimos textos, sobre todo el dedicado a Leibniz, quizá nunca pudo encontrar la respuesta a su actitud silente. De cualquier manera, Gaos no pudo dejar de reconocer en su maestro una relación inversamente proporcional a sus logros y estilos, tal como lo llegó a escribir en su diario: "Ortega, por literato, no [es] filósofo, [pero] yo [por] no [ser] literato, [soy] un analítico desecado" (Valero, 2015:101). 


\section{Notas}

${ }^{1}$ No deja de ser inquietante el paralelismo que se encuentra con otra "razón del silencio", como la que pudo esbozar el escritor mexicano Juan Rulfo, cuando se le preguntó por qué ya no había publicado luego del éxito de El llano en llamas (1953) y Pedro Paramo (1955). La respuesta: "Falta algo de esperanza" (Lizalde, s/f: minuto 14:42). Pero también, en esa misma entrevista, Rulfo vincula la escritura con las muertes ocasionadas por la Revolución mexicana, como si la sangre derramada hubiera sido la condición esencial de aquella. Sangre que es la tinta con la que se escribe la muerte: "Ya no hay mucha sangre que derramar en México”. Con una declaración como esta se cierra el ciclo de la novela mexicana revolucionaria.

${ }^{2}$ El tema del silencio es apasionante en Zambrano, al grado de recordarlo como si, de manera anticipada, compartiera la estética vanguardista a partir de, por ejemplo, las fotografías de Juan Rulfo o Gabriel Figueroa, a su llegada a Morelia, en los primeros momentos de su exilio en México: "Yo llegué a México invitada por la Casa de España, que muy pronto se llamaría Colegio de México. Era un gesto realmente inusitado, ningún país nos quería a los refugiados españoles, sólo México, sólo México, no me cansaría de decirlo, como una oración. Sólo México nos abrazó, nos abrió camino [...] Ya profesora de Filosofía como lo era en España, comencé a impartir clases el mismo día que cayó Madrid en manos de los autollamados salvadores en la Universidad de Morelia [...]. Comencé a dar mi clase en medio de ese silencio, en ese que tiene el indito, y lo digo con todo cariño, en ese silencio del indito mexicano. Y cómo me escucharon, cómo me arroparon. Su silencio fue para mí como un encaje, como una envoltura o una mantilla de esas que les ponen a los niños que tiemblan" (Lizaola, 2008:108).

${ }^{3}$ Reúne un curso impartido en 1933 en Santander y otro en Argentina, en 1939.

${ }^{4}$ En José Ortega y Gasset y la razón práctica, Pedro Cerezo Galán (2011) abunda en la importancia de este último en las formulaciones de las Meditaciones.
${ }^{5}$ Las citas corresponden a De camino al habla (Vattimo, 1992).

${ }^{6}$ Por lo demás, Aurelia Valero (2015:94) señala que uno de los más firmes distanciamientos de Gaos con Ortega fueron unas declaraciones de este con relación a su mentor mexicano, Alfonso Reyes, hechas en 1947, quien por otro lado había sido uno de los introductores en México, a inicios de la década de 1910, del autor de las Meditaciones del Quijote.

${ }^{7}$ Paradójicamente, Emilio Uranga, uno de sus más consagrados discípulos, del grupo Hiperión, autor de Análisis del ser del mexicano en 1952, habrá de criticarlo y distanciarse de él en una agria polémica, casi al final de su vida en México, en términos análogos. Uranga recordó a Gaos de esta manera: "lo que particularmente le atraía y nos contagió fueron las ideas sobre la muerte, nuestra muerte, mi muerte. Ésta era la revelación, el motivo cardinal que lo atraía en el libro de Heidegger. Y tuvo enormes consecuencias. La primera de todas hacer de José Gaos un ente moribundo, entregado a la muerte y no a la vida (Uranga, 2016:144).

\section{Referencias}

Cerezo Galaz, Pedro (2011). José Ortega y Gasset y la razón práctica. Madrid: Biblioteca Nueva.

Gaos, José (1957). Sobre Ortega y Gasset y otros trabajos de Historia de las Ideas en España y la América Española. México: Imprenta Universitaria.

Laffranque, Marie (1984). "De la guerra al exilio: María Zambrano y el senequismo de los años cuarenta”. En Cuadernos Hispanoamericanos, 413, noviembre, 103-120.

Lizalde, Enrique (s/f). "Memoria de un aparecido: Juan Rulfo" [entrevista documental]. En Canal 22. Disponible en https://www.youtube.com/ watch?v=nsLbBt3ljWY\&et=164ls (consultado el $1 \mathrm{lde}$ marzo de 2018).

Lizaola, Julieta (2008). “María Zambrano en México”. En Revista de Hispanismo Filosófico, 13, 107-112.

Merleau-Ponty, Maurice (2006). Elogio de la filosofía y lenguaje indirecto y las voces del silencio. Buenos Aires: Nueva Visión. 
Ortega y Gasset, José (1969). La rebelión de las masas. (Con un prólogo para franceses y un epílogo para ingleses y un apéndice: dinámica del tiempo). Madrid: Espasa Calpe.

Ortega y Gasset, José (1994). Meditaciones del Quijote. Ideas sobre la novela. México: Espasa Calpe.

Pereda, Carlos (2008). Los aprendizajes del exilio. México: Siglo XXI.

Recasens Siches, Luis (1970): "Gaos y José Ortega y Gasset”. En Dianoia, 16(16), 279-287.

Uranga, Emilio (2016). Algo más sobre José Gaos. Advertencia, edición y selección de Adolfo Castañón. México: El Colegio de México.

Valero, Aurelia (2015). José Gaos en México. Una biografía intelectual (1938-1969). México: El Colegio de México. Vattimo, Gianni (1992). Más allá del sujeto. Nietzsche, Heidegger y la hermenéutica. Barcelona: Paidós.

Zambrano, María (s/f) Pensamiento y poesía de la vida española. En Web Cervantes Virtual. Disponible en http:// www.cervantesvirtual.com/obra-visor/pensamiento-y-poesia-en-la-vida-espanola--0/html/ffl6a76e82bl-1ldf-acc7-002185ce6064_6.html

Zambrano, María (1996). La Cuba secreta y otros ensayos. Madrid: Endymión.

Zambrano, María (201la). Escritos sobre Ortega (Ricardo Tejada, ed.). Madrid: Trotta.

Zambrano, María (201lb). Notas de un método. Madrid: Tecnos. 